\title{
Identification and Characterization of the DMRT11E Gene in the Oriental River Prawn Macrobrachium nipponense
}

\author{
Yabing Wang ${ }^{1}{ }^{\oplus}$, Shubo Jin ${ }^{2}$, Hongtuo Fu ${ }^{1,2, *}$, Hui Qiao ${ }^{2}$, Shengming Sun ${ }^{2}{ }^{\oplus}$, Wenyi Zhang ${ }^{2}$, \\ Sufei Jiang ${ }^{2}$, Yongsheng Gong ${ }^{2}$, Yiwei Xiong ${ }^{2}$ and Yan $\mathrm{Wu}^{2}$ \\ 1 Wuxi Fisheries College, Nanjing Agricultural University, Wuxi 214081, China; wang113013@126.com \\ 2 Key Laboratory of Freshwater Fisheries and Germplasm Resources Utilization, Ministry of Agriculture, \\ Freshwater Fisheries Research Center, Chinese Academy of Fishery Sciences, Wuxi 214081, China; \\ jinsb@ffrc.cn (S.J.); qiaoh@ffrc.cn (H.Q.); sunsm@ffrc.cn (S.S.); zhangwy@ffrc.cn (W.Z.); jiangsf@ffrc.cn (S.J.); \\ gongys@ffrc.cn (Y.G.); xiongyw@ffrc.cn (Y.X.); wuy@ffrc.cn (Y.W.) \\ * Correspondence: fuht@ffrc.cn; Tel.: +86-510-8555-8835; Fax: +86-510-8555-3304
}

Received: 13 March 2019; Accepted: 5 April 2019; Published: 8 April 2019

\begin{abstract}
The doublesex and mab-3 related transcription factor (DMRT) gene family involvement in sex development is widely conserved from invertebrates to humans. In this study, we identified a DM (Doublesex/Mab-3)-domain gene in Macrobrachium nipponense, which we named MniDMRT11E because it has many similarities to and phylogenetically close relationships with the arthropod DMRT11E. Amino acid alignments and structural prediction uncovered conservation and putative active sites of the DM domain. Real-time PCR analysis showed that the MniDMRT11E was highly expressed in the ovary and testis in both males and females. Cellular localization analysis showed that DMRT11E was mainly located in the oocytes of the ovary and the spermatocyte of the testis. During embryogenesis, the expression level of MniDMRT11E was higher at the cleavage stage than at other stages. During the different stages of ovarian development, MniDMRT11E expression gradually increased from OI to OIII and decreased to the lowest level at the end of OIV. The results indicated that MniDMRT11E probably played important roles in embryonic development and sex maturity in M. nipponense. MniDMRT11E dsRNA injection also significantly reduced vitellogenin $(V G)$ expression and significantly increased insulin-like androgenic gland factor (IAG) expression, indicating a close relationship in gonad development.
\end{abstract}

Keywords: Macrobrachium nipponense; DMRT11E; temporal and spatial expression; in situ hybridization; RNA interference

\section{Introduction}

The oriental river prawn, Macrobrachium nipponense, is an economically important freshwater prawn and is widely farmed in China, with an annual production of almost 240,739 tons in 2017 [1]. Male oriental river prawns grow faster than females. The average size of the male commodity is 2-2.5 times that of females. All male cultures will help to increase yields and economic value. The development of an all-male culture in M. nipponense is based on sexual control technology. Therefore, it is important to identity sex-determining genes and their regulatory mechanism.

Various sex determination methods in animals are the focus of current research. Sex-determining methods in insects that are close to crustaceans have recently been studied, especially in model species such as Drosophila [2,3]. The sex determination mechanism of crustaceans is relatively complex and impacted by environmental factors. At present, there are limited studies, and most species-related studies are still lacking. Insulin-like androgenic gland factor $(I A G)$ is a unique gene in crustaceans 
that is specifically expressed in the androgenic gland (AG), and also plays an important role in sex differentiation, but the specific molecular mechanism is not yet clear [4-8].

The molecular pathways of sex determination and differentiation are highly diverse in the sexual reproduction of animals. This has been interpreted as a result of the rapid evolution of the genes involved in the process [9]. However, the mechanism of sex determination is different in different animal lineages [10]. In insects, cell-based autonomic and splicing-based mechanisms have been shown to be responsible for sex dimorphism; while in mammals, gonadal-dependent endocrine control features can differentially determine and maintain male and female phenotypes [11]. Although different upstream mechanisms are involved in sex determination, downstream-related genes appear to be more conservative [12]. Among the most widely studied genes are the doublesex and mab-3 related transcription factor (DMRT) gene families [13]. DMRT proteins share a distinctive zinc-finger DNA binding motif termed the DM domain [14-16]. Doublesex $(d s x)$, the first gene, was originally discovered at the bottom of the Drosophila melanogaster sex determination cascade [17]. Another DM domain gene, mab-3, is required for the synthesis of vitellin and the male-specific lineage in Caenorhabditis elegans [18]. Members of the DMRT gene family are widely represented in the animal kingdom. For example, DSX is only found in arthropods, DMRT1 is only found in vertebrates, and DMRT6-9 are only found in mammals [19].

The DMRT gene has been studied for decades in vertebrates, nematodes, and insects; however, interest in crustaceans is comparatively recent [10]. The first crustacean DM-domain gene from Eriocheir sinensis represents a testis-specific expression pattern [9]. In addition, the Daphnia magna, DmaDsx1, exhibits a pattern of sexual dimorphism and is responsible for male-specific development [20]. Two $D M R T$ genes were also found in Macrobrachium rosenbergii, which is closely related to M. nipponense, and one of these was found to be related to the expression of $I A G$ [10]. In crustaceans, genes encoding the DM-domain (DM-domain genes) may play a related role in sex determination $[9,10,20]$.

In decapod crustaceans, as in vertebrates, the vitellogenesis oocyte is a huge growing oocyte with a cytoplasm filled with eosinophilic cells. Early vitellogenesis oocytes contain yolk granules and blocks deep into the yolk, and the nucleus is located in the center of the oocytes. The mature period of the oocytes, with the greatest volume, is in the late vitellogenesis stage. The nucleus surrounds the oocyte and, eventually, the germinal vesicle breaks down and the nuclear membrane disappears. The egg around the follicular cell layer then becomes extremely thin [21]. The testes contain many seminiferous tubules. Each small tubule is made up of germinative epithelium and a tubule liner. The germinative epithelium produces a variety of spermatogeni cell areas. The vas deferens can be morphologically divided into three regions: the anterior; the median, which is highly convoluted; and the posterior. The vas deferens is composed of columnar epithelium surrounded by striated muscle. Two types of cells, high columnar cells and low columnar cells, which can secrete spermatophore matrixes, can be distinguished in the epithelium of the vas deferens. The terminal ampulla is highly muscularized [9,22,23]. The AG is located at the end of the vas deferens and the ejaculatory bulb [24]. The AG is a small lobular endocrine organ [25]. The AG of Macrobrachium possesses three cell types: Type I cells are small polygonal shaped-cells, and stain strongly with hematoxylin-eosin (H\&E); type II cells are slightly larger, and stain lightly with H\&E; and type III cells are similar in size and shape to type I cells, but the cytoplasm is unstained [25].

In this study, we isolated and characterized a gene with a DM domain in M. nipponense. Homology comparison and phylogenetic analysis of putative proteins indicate that it is a member of the MniDMRT11E subfamily. Tissue distribution analysis of DMRT11E transcription levels in the gonads was significantly higher than in other tissues. In addition, the knockdown of MniDMRT11E had a significant impact on the transcriptional expression level of MnIAG and MnVG. 


\section{Results}

\subsection{Molecular Cloning and Structural Analysis of DMRT11E Gene}

The full length of the cloned single DMRT cDNA is 2585 bp (GenBank accession number, MH636338) and encodes 542 amino acids. The $5^{\prime}$-untranslated region (UTR) is $200 \mathrm{bp}$ long, and the $3^{\prime}$-UTR is $756 \mathrm{bp}$ long. The termination codon and polyadenylation signal located on the $3^{\prime}-\mathrm{RACE}$ PCR product revealed the integrity of the sequences we cloned (Figure 1). The sequence obtained from the 3'-RACE PCR product contained a stop codon. The homologous comparison (Figure 2a) and phylogenetic analysis (Figure 3) revealed it was most closely related to the DMRT11E subfamily of the DMRT protein family; therefore, we refer to the gene as MniDMRT11E. Blast searches showed that the protein structure of MniDMRT11E was similar to that of the following species: Macrobrachium rosenbergii (DMRT11E, 93\%), Sagmariasus verreauxi (DMRT11E, 76\%), Daphnia magna (DMRT11E, 53\%), Amazona aestiva (DMRT2 48\%), and Fundulus heteroclitus (DMRT2, 47\%).

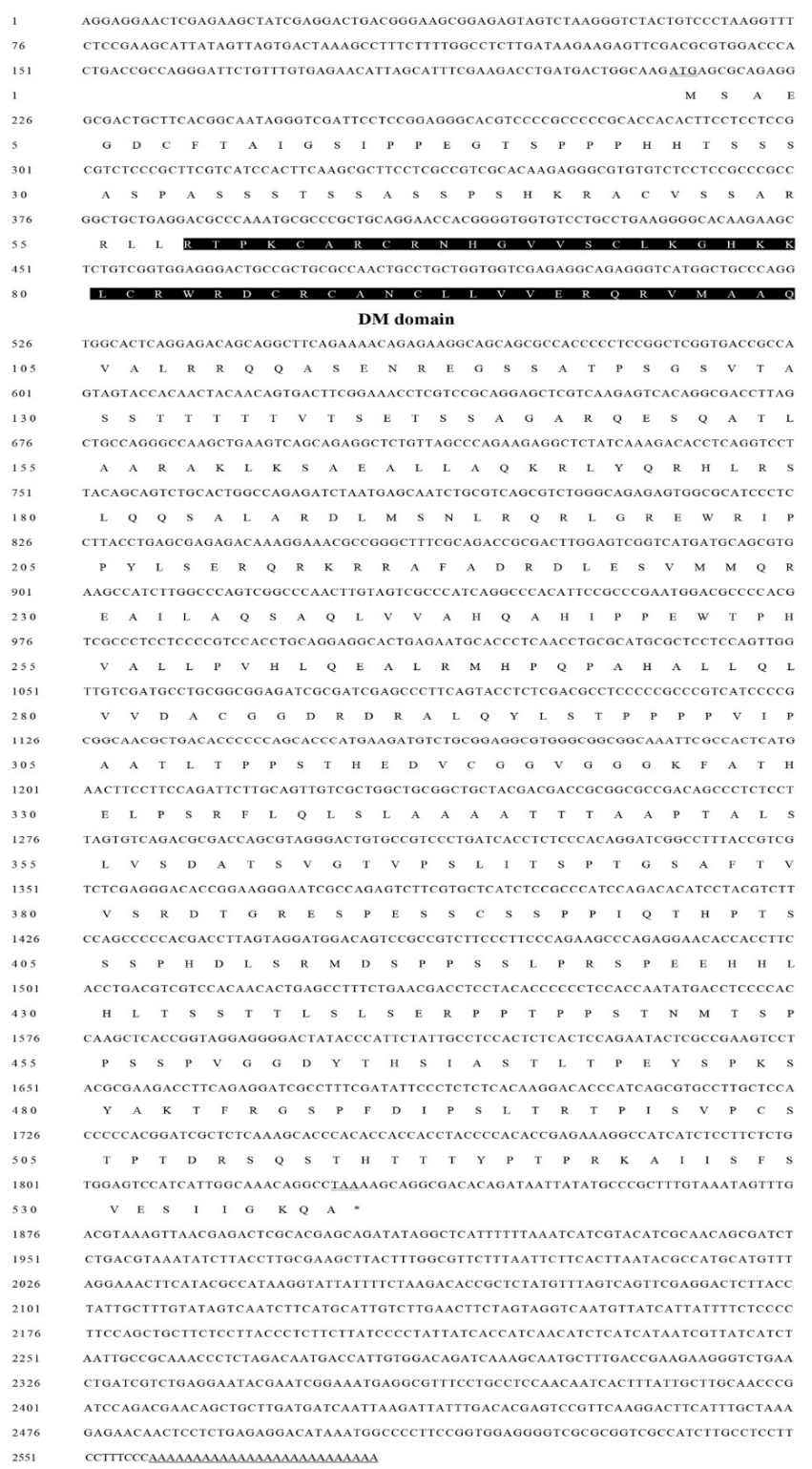

Figure 1. Nucleotide and deduced amino acid sequence of Macrobrachium nipponense DMRT11E gene (MniDMRT11E) cDNA. 5' UTR and 3' UTR are listed with lowercase letters. ORF are shown by capital letters. The translation start codon (ATG) and termination codon (TAA) are underlined in the figure. The DM domain is marked with shadow. 
a

MnidMRTIIE DM MrODMRT11E_DM MroDMRT 99B DM SveDMRTIIE DM TruDMRT3 DM TrUDMRT5 DM XIaDMRT1_DM XlaDMRT2 DM XI ADMRT4_DM XlaDMRT5 DM XtrDMRT 3 DM DbUDMRT 11E_DM DbuDMRT 99B DM DMaDMRT11E_DM DMaDMRT 99B DM DMEDMRTIIE DM DMeDSX1_DM DMeDSX2 DM DMeDSX3_DM

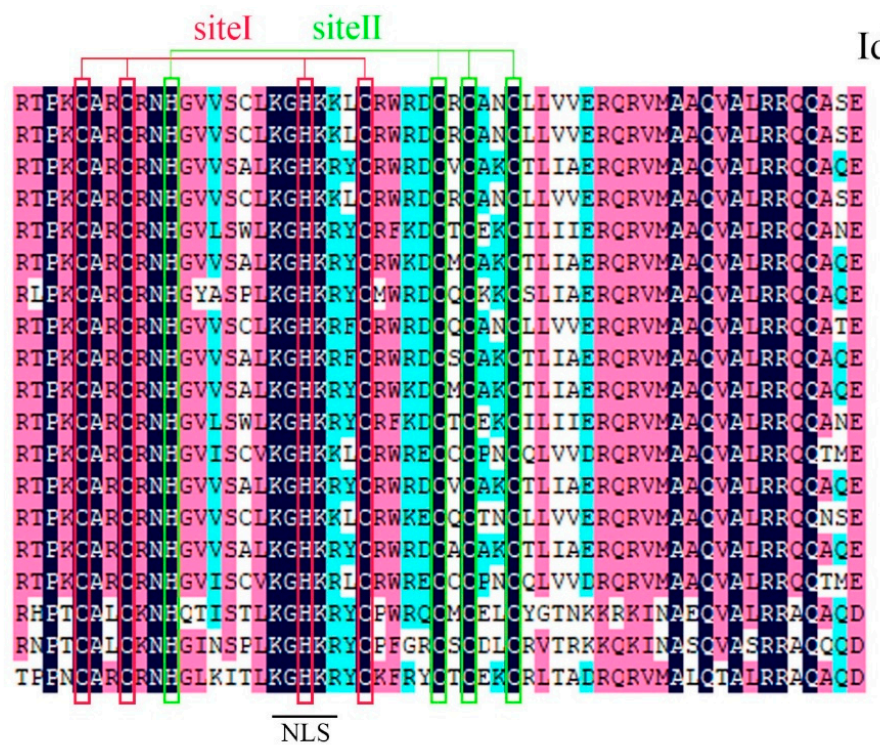

Identity $(\%)$

100

100

82.76

98.28

75.86

81.03

74.14

91.38

82.76

81.03

75.86

82.76

82.76

89.66

82.76

81.03

48.28

44.83

56.90

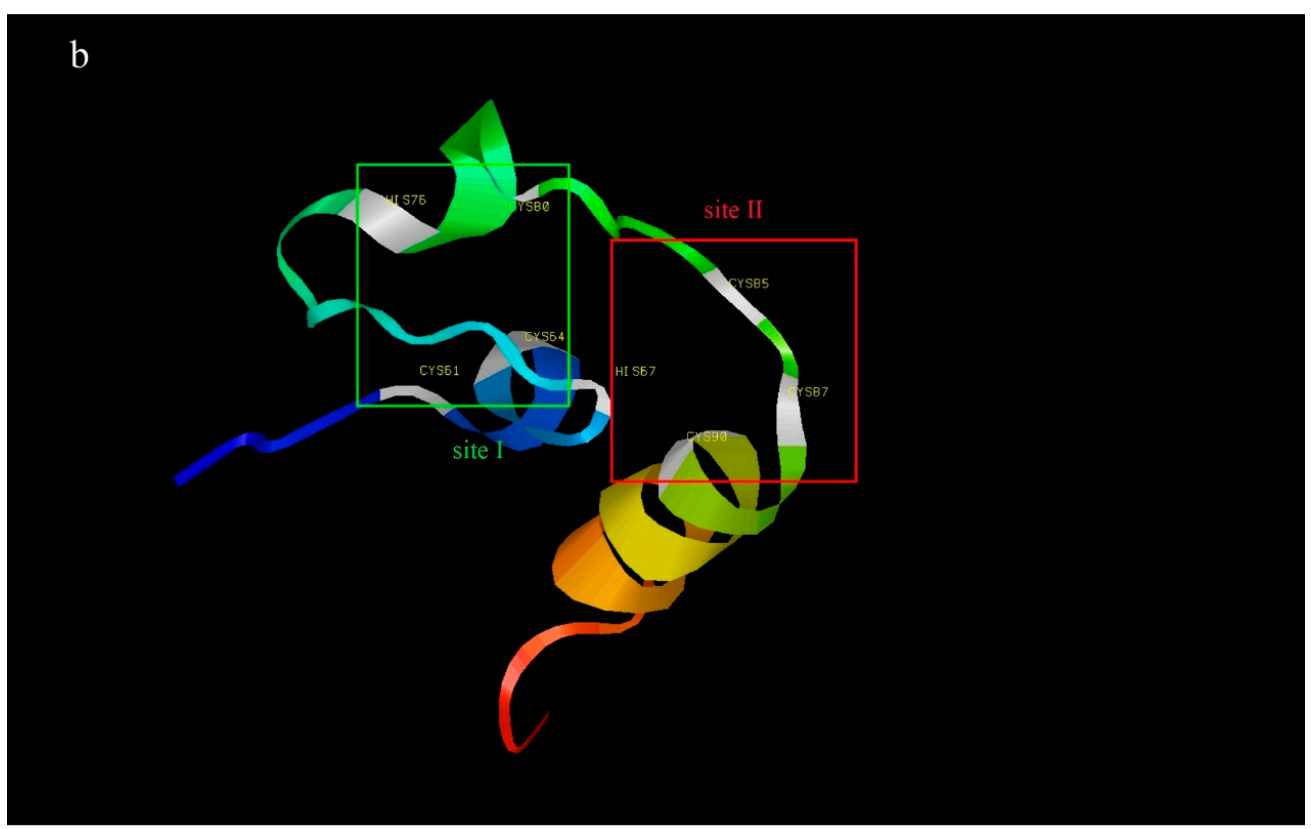

Figure 2. Amino acid alignment and structure prediction of DM domains of MniDMRT11E. (a) Homologous comparison of amino acid sequences of DM domains from various DMRT proteins. Consensus amino acids are highlighted. The right columns show the identities of MniDMRT11E_DM with other DMRT proteins (MniDMRT11E_DM (In this study), MroDMRT11E_DM (Macrobrachium rosenbergii AHI47024.1), MroDMRT99B_DM (Macrobrachium rosenbergii AHI47025.1), SveDMRT11E_DM (Sagmariasus verreauxi ARK36622.1), TruDMRT3_DM (Takifugu rubripes NP_001033034.1), TruDMRT5_DM (Takifugu rubripes NP_001033039.1), XlaDMRT1_DM (Xenopus laevis NP_001089969.1), XlaDMRT2_DM (Xenopus laevis NP_001089725.1), XlaDMRT4_DM (Xenopus laevis AAV66322.1), XlaDMRT5_DM (Xenopus laevis NP_001089148.1), XtrDMRT3_DM (Xenopus tropicalis NP_001243149.1), DbuDMRT11E_DM (Drosophila busckii ALC49006.1), DbuDMRT99B_DM (Drosophila busckii ALC47170.1),DMaDMRT11E_DM (Daphnia magna BAG12871.1), DMaDMRT99B_DM (Daphnia magna BAG12873.1),DMeDMRT11E_DM (Drosophila melanogaster NP_511146.2), DMeDSX1_DM (Drosophila melanogaster NP_731197.1), DMeDSX2_DM (Drosophila melanogaster NP_731198.1), DMeDSX3_DM (Drosophila melanogaster NP_524272.4)). Putative nuclear localization signals (NLSs) are underlined. (b) 3D-structures of MniDMRT11E predicted by I-TASSER. Green rectangle (site I) and red rectangle (site II) represent the residues of two intertwined $\mathrm{Zn}^{2+}$-binding sites. 


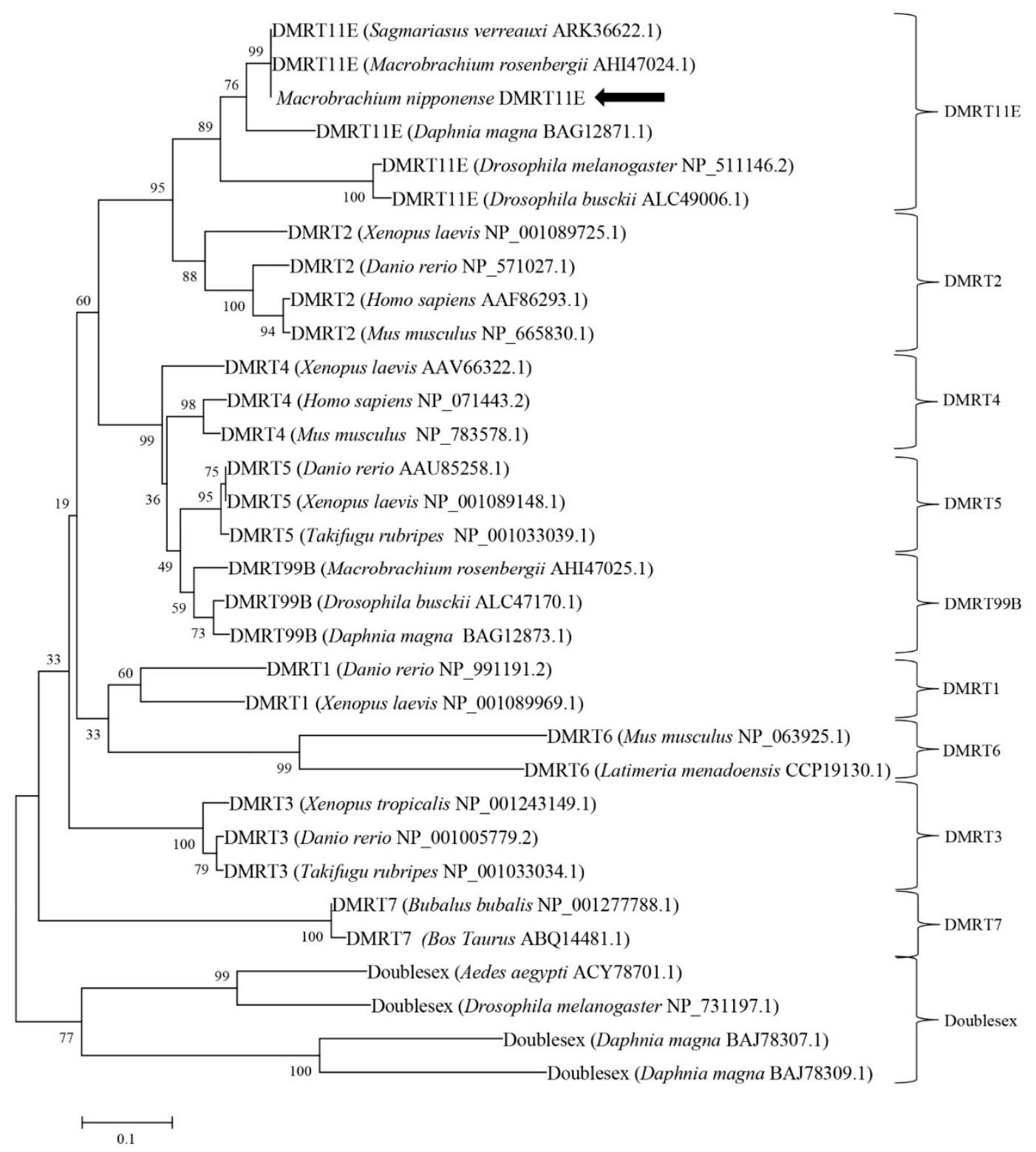

Figure 3. Phylogenetic analysis of DM family members. The diagram was generated by the neighbor-joining method using the MEGA 5.1 program. Bootstrapping replications were 1000. GenBank accession numbers are in brackets.

In MniDMRT11E, the two intertwined $\mathrm{Zn}^{2+}$-binding sites (sites I C61/C64/H76/C80 and sites II H67/C85/C87/C90) are necessary for DNA binding (Figure 2). The DM domain also contains a conserved nuclear localization signal (NLS) (Figure 2a). DM domains are more conserved in DMRT11Es $(81.03-100 \%)$ and are similar to vertebrate DMRT2s $(91.4 \%)$.

\subsection{Tissue-Specific Expression Patterns of MniDMRT11E}

The expression levels were analyzed in adult prawn tissues by qPCR, and the results showed that MniDMRT11E mRNA was distributed in all tissues (Figure 4). MniDMRT11E was highest in the testis $(p<0.05)$, followed by the ovary $(p<0.05)$. MniDMRT11E was expressed more highly in the male hepatopancreas than in the female. However, the level of expression in the muscles was the opposite. 


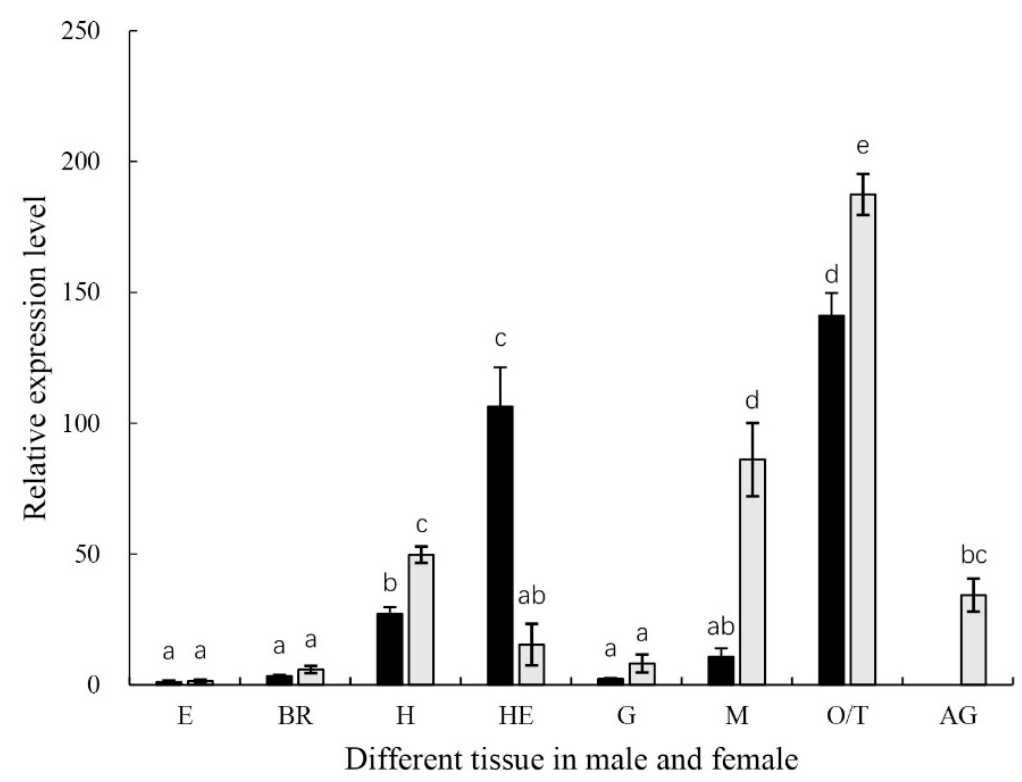

Figure 4. The expressions of MniDMRT11E revealed by qPCR in different tissues. The amount of two genes' mRNA was normalized to the $\beta$-actin transcript level. Data are shown as means $\pm \operatorname{SD}(n=4$ prawns). E: eyestalk; BR: brain; H: heart; HE: hepatopancreas; G: gill; M: muscle; O: ovary; T: testis; AG: abdominal ganglia. Statistical analyses were performed with one-way ANOVA analysis. The post-hoc test following ANOVA analysis used LSD. Bars with different letters were considered significant at $p<0.05$. Values are means \pm standard error of the mean (SE) for quadruplicate samples.

\subsection{Expression of the MniDMRT11E Gene During Embryo Stages}

The MniDMRT11E expression pattern was analyzed by qPCR in different developmental stages (from the cleavage stage to the first-day larvae after hatching) (Figure 5). A relatively high level of MniDMRT11E expression was observed in the cleavage stage of embryos $(p<0.05)$. The expression at other developmental times was not significant $(p>0.05)$.

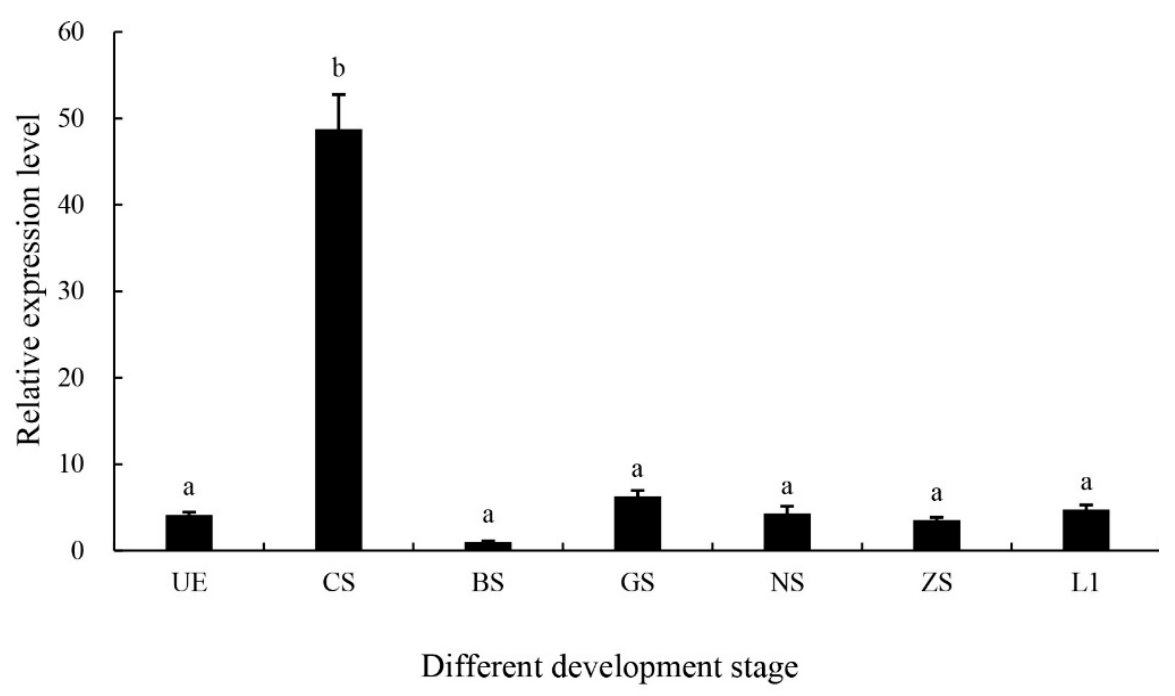

Figure 5. The expressions of MniDMRT11E revealed by qPCR in different embryo stages. The amount of MniDMRT11E mRNA was normalized to the $\beta$-actin transcript level. UE: unfertilized egg; CS: cleavage stage; BS: blastula stage; GS: gastrula stage; NS: nauplius stage; ZS: zoea stage; L1: the first day larvae after hatching. Data are shown as means $\pm \mathrm{SD}(n=4$ prawns). Statistical analyses were performed with one-way ANOVA analysis. The post-hoc test following ANOVA analysis used LSD. Bars with different letters were considered significant at $p<0.05$. Values are means \pm standard error of the mean (SE) for quadruplicate samples. 


\subsection{Expression of the MniDMRT11E Gene in Different Developmental Stages of the Ovaries}

Figure 6 shows the expression patterns of MniDMRT11E throughout the reproductive cycle, assessed by qPCR. The results confirmed a regular expression throughout the maturation of the ovary. The MniDMRT11E transcript level was low at the beginning of the reproductive cycle (stage I, undeveloped stage) and increased to a maximum at the nearly-ripe stage (stage III). Beyond this stage, the level fell to the lowest level at the ripe stage (stage IV). This implies that MniDMRT11E may play a role in reproductive development.

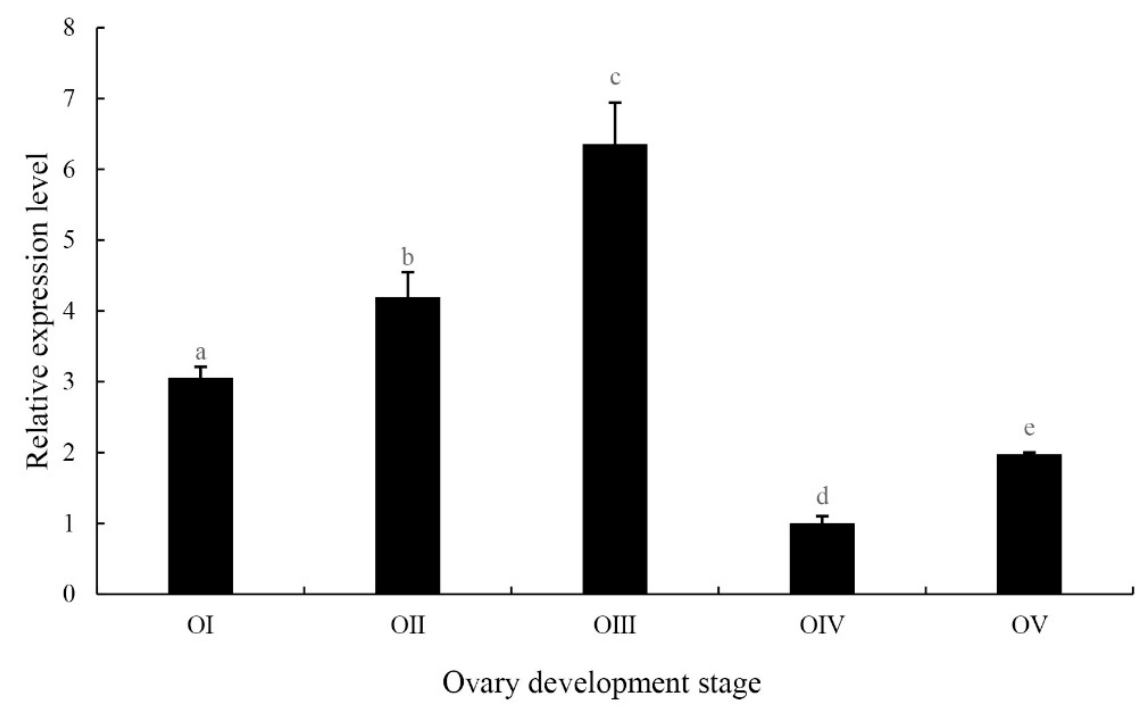

Figure 6. Quantitative analysis of MniDMRT11E transcripts using real-time PCR in different development stages of ovaries. O I: undeveloped stage; O II: developing stage; O III nearly-ripe stage; O IV: ripe stage; O V: spent stage. Data are shown as means $\pm \mathrm{SD}$ ( $n=4$ prawns). Bars with different letters were considered significant at $p<0.05$. Statistical analyses were performed with one-way ANOVA analysis. The post-hoc test following ANOVA analysis used LSD. Values are means \pm standard error of the mean (SE) for quadruplicate samples.

\subsection{Localization of the MniDMRT11E Gene in the Gonad}

According to previous results [26] and ovary color observation, the ovarian cycle of prawns was divided into five stages: transparent (undeveloped, oogonium proliferation, Stage I), yellow (developing, primary vitellogenesis, Stage II), light green (nearly-ripe, secondary vitellogenesis, Stage III), dark green (ripe, vitellogenesis termination, Stage IV), and gray (spent, Stage V) (Figure 7A). The cellular localization of MniDMRT11E was examined in different development stages of ovaries by in situ hybridization. ISH revealed a MniDMRT11E signal in the same locations in all the oocytes types (Figure 7B). The signal was visualized in all of the oocyte types, including yolk granules, the nucleus, and the cytoplasmic membrane (Figure 7B). The signal appearance in the cytoplasm was closed to the nucleus.

The male reproductive system consists of paired testes, vas deferens, terminal ampulla, and male gonopore. In mature testes, the MniDMRT11E mRNA was visualized in spermatogonia during spermatogenesis (Figure 8). In vas deferens, the MniDMRT11E mRNA was visualized in the eosinophilic matrix (Figure 8), and in the androgenic gland, the MniDMRT11E mRNA was visualized in the nucleus and cell membrane of three glandular cells (Figure 8). 
A

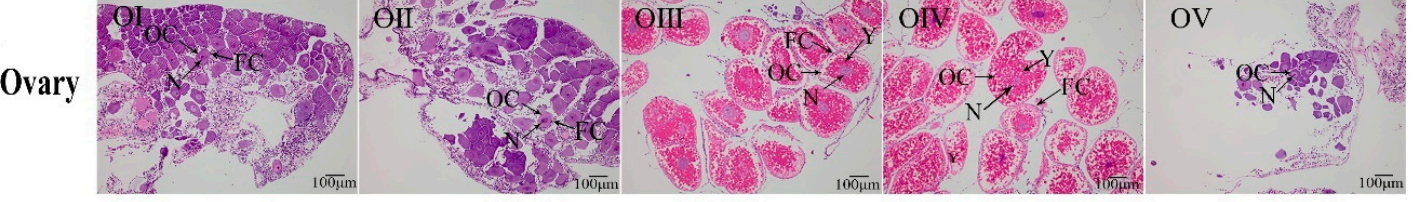

B

HE

Probe

Control
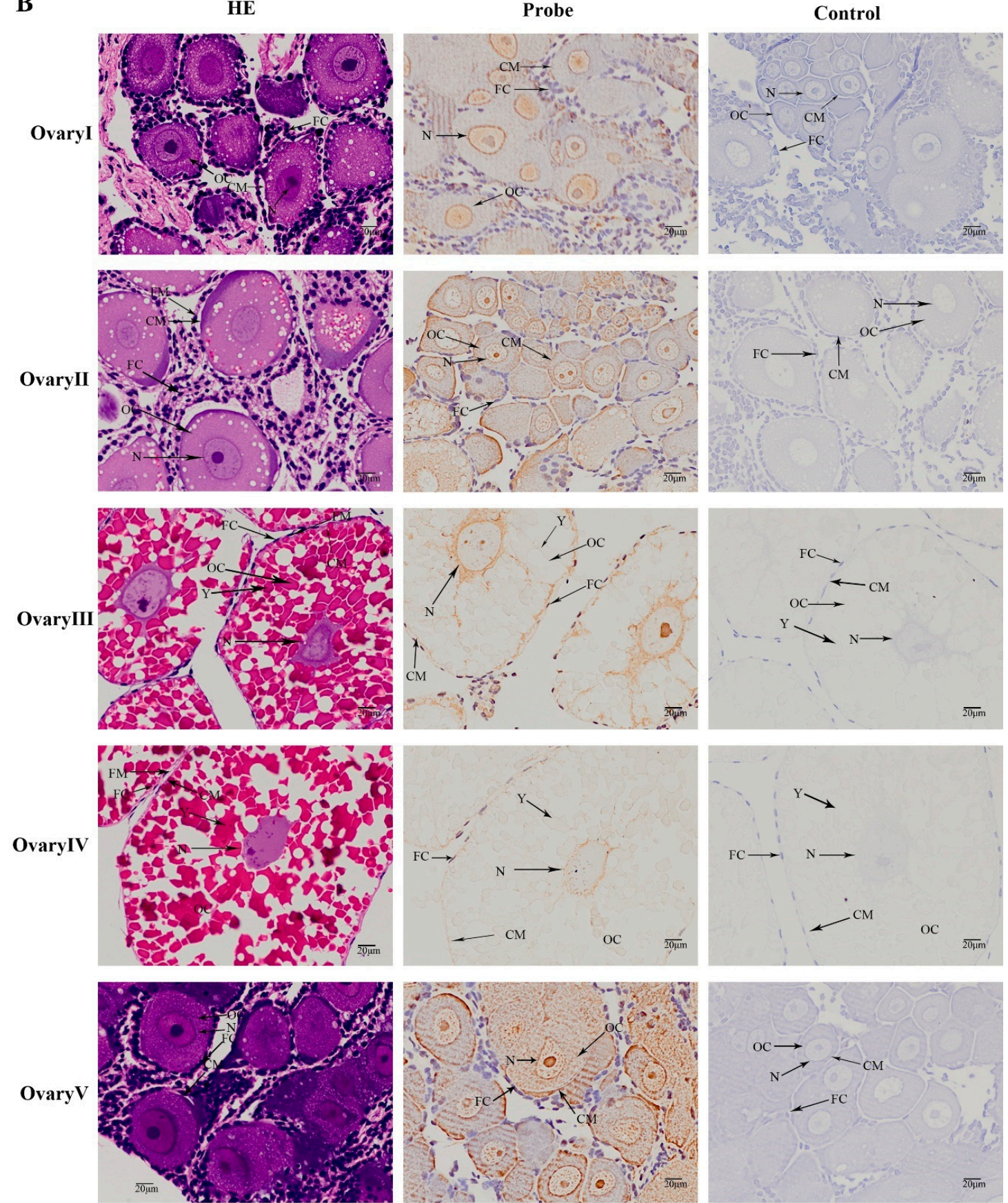

Figure 7. (A) Photograph of M. nipponense ovary in ovarian cycle. OG: oogonium; OC: oocyte; N: nucleus; CM: cytoplasmic membrane; Y: yolk granule; FC: follicle cell. (B) Histological section of ovary at different ovary stages of $M$. nipponense. OG: oogonium; OC: oocyte; N: nucleus; CM: cytoplasmic membrane; Y: yolk granule; FC: follicle cell; FM: follicle membrane. (A) scale bars: $100 \times$. (B) scale bars: $400 \times$. 

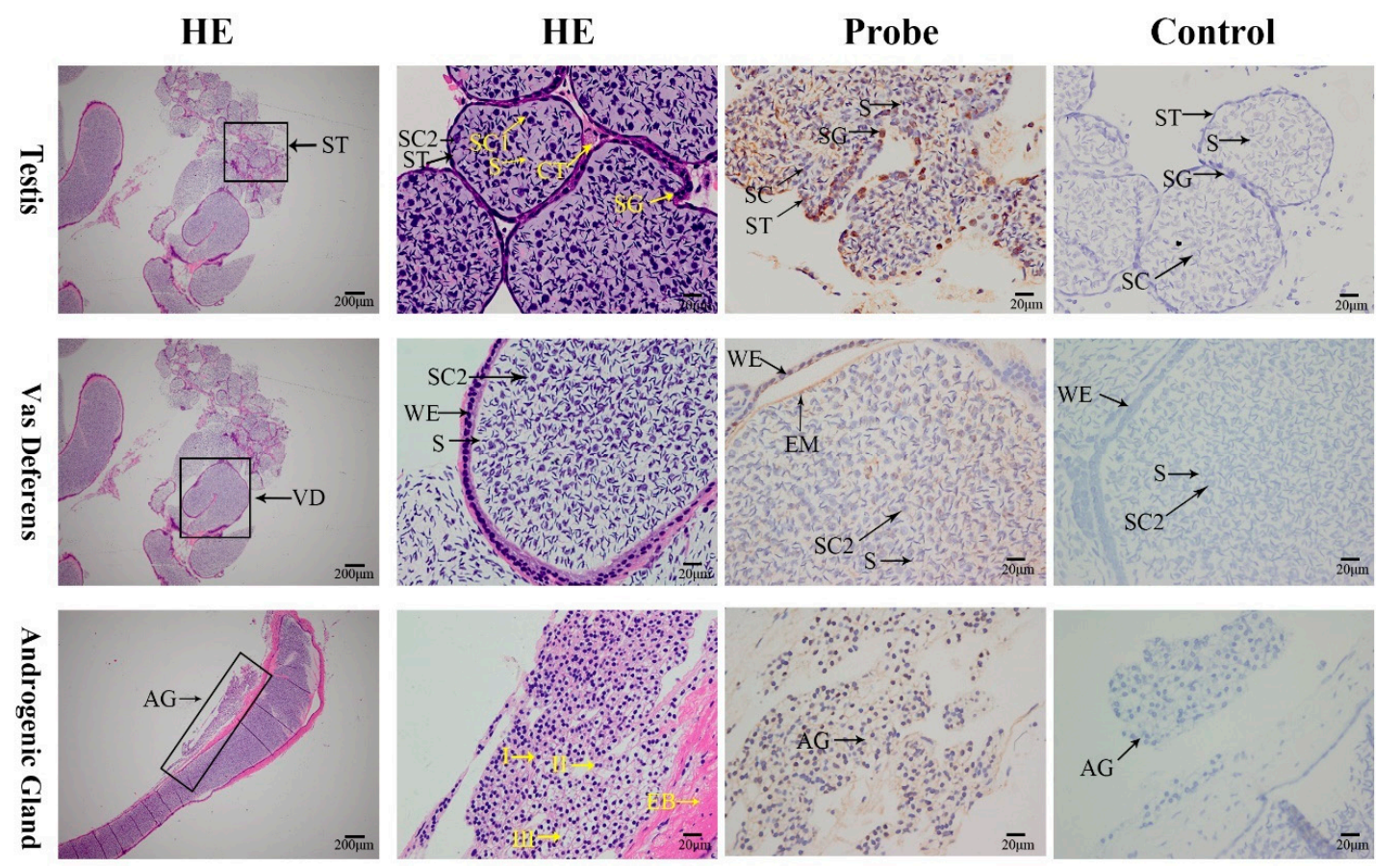

Figure 8. Histological section of testis of M. nipponense. CT: collecting tissue; SG: spermatogonium; SC: spermatocyte; SC1: primary spermatocyte; SC2: second spermatocyte; ST: spermatid; S: sperm. WE: wall epithelium; EM: eosinophilic matrix; VD: vas deferens; EB: the ejaculatory bulb; AG: androgenic gland. Within each lobule, there are three types of cells (I, II, and III). The first column: scale bars: 40×, others: scale bars: $400 \times$.

\subsection{Effects of MniDMRT11E Knockdown on Gonad by RNAi}

Considering that MniDMRT11E exhibits a dimorphic expression pattern, we used RNAi to investigate the role of MniDMRT11E function in male/female phenotypic development/maintenance of M. nipponense. Intravenous injection of RNAi-mediated knockout with dsRNA was apparently successful, and on the seventh day after injection, MniDMRT11E expression was down-regulated by $86 \%$ ( $p<0.01$, Figure 9A) compared with control levels. After MniDMRT11E RNAi, we observed that the $V G$ (female) transcript decreased significantly by $60 \%$ in the ovary and $94 \%$ in the hepatopancreas $(p<0.01$, Figure 9B). However, we observed a nearly two-fold increase in the IAG transcript $(p<0.01$, Figure 9C). These results indicated that MniDMRT11E RNAi reduced $V G$ accumulation and increased $I A G$ accumulation. 


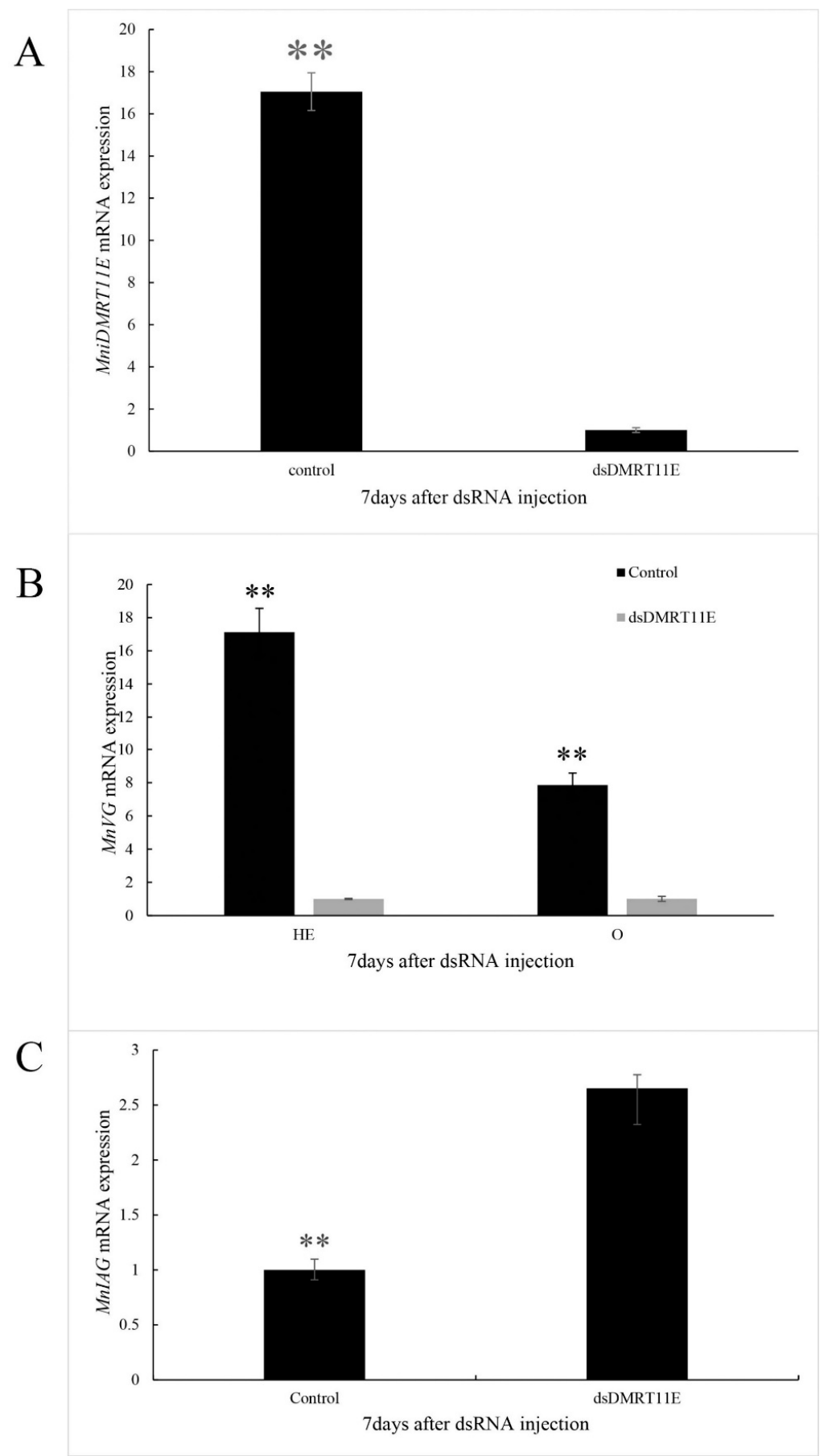

Figure 9. The MniDMRT11E expression level (A) after RNA interference. Vitellogenin (VG) (GenBank: KJ768657) expression level in the ovary and hepatopancreas and (B) after RNA interference in female specimens. Insulin-like androgenic gland factor (IAG) (GenBank: KF811212) expression level (C) in the abdominal ganglia after RNA interference in male specimens. HE: hepatopancreas; O: ovary. Results are expressed as mean \pm SEM and significance of comparison is defined as $p<0.01\left({ }^{* *}\right)$ by Student's $t$ tests.

\section{Discussion}

DMRT or dmrt-like genes have been cloned in several invertebrates, but due to a lack of genomic information, it is difficult to annotate and identify DMRT genes in different invertebrate groups [27,28]. In this study, we identified a DMRT gene corresponding to MniDMRT11E in M. nipponense and performed a series of in silico analyses, such as amino acid translation, domain/motif identification 
and comparison, and phylogenetic analysis, to characterize the MniDMRT11E gene [22]. This is the first gene with a DM-domain to be identified in M. nipponense and it was shown that the DM domain was well-conserved, as in other species. All DMRT amino-acid sequences contain a single conserved DNA-binding motif known as the DM domain. The DM motif was a cysteine-rich DNA-binding domain comprising interwoven $\mathrm{CCHC}$ and $\mathrm{HCCC} \mathrm{Zn}^{2+}$ binding sites and a putative nNLS consisting of KGHKK/R (Figure 2) [29]. Phylogenetic analysis indicated that the MniDMRT11E protein clustered with the DMRT11E sequences of other species.

The DMRT11E gene is usually expressed in a sex-specific manner in many species. In Drosophila melanogaster, three DM genes were identified: DMRT11E, DMRT93B, and DMRT99B. Quantitative gene expression analysis in gonads showed that DMRT11E is expressed higher in the ovary than in the testis [29]. In Daphnia magna, the DMRT11E was also highly expressed in the ovary [29]. However, in Macrobrachium rosenbergii, DMRT11E transcription was prominent in the testis, while much lower in the ovary [10]. In our study, DMRT11E transcription was prominent in both the testis and ovary; moderate in hepatopancreas (female) and muscle (male); and much lower in the eyestalk, brain, and gill (Figure 4) $(p<0.05)$. However, the levels were much higher in the testis than in the ovary. The expression profile of the MniDMRT11E is quite similar to that of Macrobrachium rosenbergii MroDMRT11E in the testis [10]. The cellular localization of the MniDMRT11E transcripts has also been examined in spermatogonia in the testis and oocyte in the ovary. Together, these findings suggest that MniDMRT11E is an important gene in gonad maturity.

During embryo stages, we founded that the abundance of MniDMRT11E mRNA in the cleavage stage is much higher than in other stages (Figure 5). Due to the elaborations in arthropods, the clues to the exact role of DMRT11E can be indicated by the function of their vertebrate homologs (DMRT2s; Figure 5). In zebrafish, two genes, $D M R T 2 a$ and $D M R T 2 b$, are present. In adult tissues, the zebrafish $D M R T 2 a$ and DMRT2 $b$ mRNA is expressed highly in muscle tissues. In different stages of embryos, $D M R T 2 b$ transcripts appear in all stages of embryos, and the level of DMRT2b transcripts increases during late development. DMRT2a transcripts appeared at the blastula stage and reached a peak at the bud stage immediately before segmentation. DMRT2a is necessary for symmetric somite formation, while DMRT2b regulates somite differentiation impacting on slow muscle development [30]. In mice, $D M R T 2$ is expressed in the dermomyotome of developing vertebrate somites [31]. This could explain why MniDMRT11E is highly expressed in muscle (male) (Figure 4).

Ovogenesis refers to the process in which primordial oogonium cells develop into oocytes cells and develop into mature eggs. Oogonium cells first mitotically propagate in the ovary, and then enter meiosis to become oocytes. In the current study, different expression patterns were also detected in the ovary. The expression level of MniDMRT11E was lower at the beginning of the reproductive cycle (stage I), and then increased and peaked at the oil globules stage (stage III), after which a decrease in levels was observed. In addition, the cellular localization of MniDMRT11E s mRNA was visualized in all the oocyte, including yolk granules, the nucleus, and the cytoplasmic membrane (Figure 5). This means it is important for oocyte development.

Among the known invertebrate model species, Caenorhabditis elegans and Drosophila have sex-determining genes called mab-3 and doublesex, respectively, which have one common DNA-binding motif in the gate (DM) domain. The DM domain has regulatory relationships with certain genes, such as $V G$ and $I A G[10,29,32-36]$. Although the foregoing results suggest a relationship between MniDMRT11E and gonad maturity, the precise function of MniDMRT11E during gonad maturity remains unclear. RNAi has been helpful in studying more and more crustaceans and revealing the function of novel crustacean genes [21,37-39]. Although the above results indicated a link between MniDMRT11E and gonadal maturation, the exact function of MniDMRT11E during gonadal maturation remains unclear. Therefore, we further investigated its function in M. nipponense by injecting MniDMRT11E dsRNA. MniDMRT11E mRNA expression was significantly inhibited seven days after the dsRNA injection in vivo compared to the control group, confirming that RNAi using dsRNA was an effective and valuable tool for studying specific gene functions by gene silencing. 
Meanwhile, MniDMRT11E RNAi caused a significant negative regulation of $V G$ gene expression in the female ovary and hepatopancreas. However, MniDMRT11E RNAi resulted in significantly positively regulation of the $I A G$ transcripts in the abdominal ganglia in males. In M. nipponense, the main sites of $V G$ synthesis are the ovary and hepatopancreas. $V G$ RNAi inhibited maturation of the ovary [38]. The relationship between MniDMRT11E and MniVG also explains the high expression of MniDMRT11E in the hepatopancreas(female) (Figure 4). In M. rosenbergii, silencing of MrIAG led to the arrest of testicular spermatogenesis and of spermatophore development in the terminal ampullae of the sperm duct, accompanied by hypertrophy and hyperplasia of the AGs. In addition, the sex reversal of male $M$. rosenbergii occurred through the silencing of a single IAG-encoding $[4,36]$. This also explains why the MniDMRT11E mRNA was visualized in glandular cells of AG (Figure 8). Considering the important involvement of $I A G$ in crustacean males [4-8,36] and the vitally important involvement of $V G$ in females [32,38,40], we hypothesized that MniDMRT11E may participate in this pathway, either directly or indirect upstream of $I A G / V G$. This result provides strong evidence for an important role of MniDMRT11E in promoting ovary maturity and inhibiting testis maturity. It is noteworthy that MroDMRT11E has a positive regulatory effect on IAG in patients with $M$. rosenbergii, but in M. nipponense, MniDMRT11E is the opposite. Crustaceans are less developed animals than vertebrates. Even in related species, the functions of the same gene among different species are different. The results of RNAi suggest that further research is needed to elucidate the function of MniDMRT11E.

In this study, we have identified a DMRT gene from Macrobrachium nipponense. These results suggested that the MniDMRT11E gene did not have dimorphic gene expression, but it could promote gonadal development, as well as embryogenetic expression patterns. The MniDMRT11E RNAi displayed negative regulation of the $V G$ gene in the ovary and hepatopancreas and positive regulation of the IAG gene in abdominal ganglia. This study advances our understanding of the biological functions of the MniDMRT11E gene in M. nipponense.

\section{Materials and Methods}

\subsection{Experimental Animals and Sampling}

Our study does not involve endangered or protected species. This study was approved by the Institutional Animal Care and Use Ethics Committee of the Freshwater Fisheries Research Center, the Chinese Academy of Fishery Sciences (Wuxi, China, FFRC125, 26 August 2016). Healthy adult prawns, M. nipponense, were collected from Tai Lake in Wuxi, China $\left(120^{\circ} 13^{\prime} 44^{\prime \prime} \mathrm{E}, 31^{\circ} 28^{\prime} 22^{\prime \prime} \mathrm{N}\right)$ in June 2017. The weight of each male prawn was $2.8 \pm 0.5 \mathrm{~g}$ and the weight of each female was $1.8 \pm 0.5 \mathrm{~g}$. All prawns were transferred to an aquarium, cultured in an inflated freshwater pool in an indoor facility, and fed parudina twice per day.

\subsection{Nucleotide Sequence and Bioinformatics Analysis}

Total RNA was extracted from different adult prawn tissues using RNAiso Plus Reagent (TaKaRa, Japan) [21]. The design of degenerate primers (DMRTDF1, DMRTDR1, DMRTDR2) was based on the highly conserved amino-acid and nucleotide sequences of DM domains (M. rosenbergii, KC801044.1; D. magna, AB361069.1; D. melanogaster, NM_169202.1). Total RNA extracted from a testis was subjected to 5'and 3' RACE cDNA syntheses using a 5'-full RACE Kit and 3'-full RACE Core Set Ver. 2.0 Kit (TaKaRa, Japan). Two-step PCR cloning with gene-specific primers (listed in Table 1) was carried out as described in [21]. The ORF Finder program (https://www.ncbi.nlm.nih.gov/orffinder/), and BLASTX and BLASTN programs (http:/ / www.ncbi.nlm.nih.gov/BLAST/) were used to deduce amino acid sequences. The spatial structure was predicted by I-TASSER (https:/ / zhanglab.ccmb.med.umich.edu/ I-TASSER/). A phylogenetic tree was generated by Molecular Evolutionary Genetics Analysis (MEGA 5.1, http:/ / www.megasoftware.net) by the neighbor-joining method with bootstrapping replications of 1000 . 
Table 1. Primers of sequence used.

\begin{tabular}{|c|c|c|}
\hline Primer Name & Sequence $\left(5^{\prime}-3^{\prime}\right)$ & Description \\
\hline DMRTD-F1 & TGCGCCMGRTGYMGRAAYCAYGG & For DM-domain RACE \\
\hline DMRTD-R1 & ARSGCSACYTGSGCSGCCATNAC & For DM-domain RACE \\
\hline DMRTD-R2 & TGSGCSGCCATNACCCKYTGCC & For DM-domain RACE \\
\hline $5^{\prime}$-RACE outer & ATTACCCGTTGCCTCT & For $5^{\prime}-\mathrm{RACE}$ \\
\hline 5'-RACE inner & ACCACCAGCAGGCAGTTG & For $5^{\prime}$-RACE \\
\hline DMRT-5'R & GCTTCTTGTGCCCCTTCA & For $5^{\prime}$-RACE \\
\hline $3^{\prime}$-RACE outer & GGTGGTGTCCTGCCTGAA & For $3^{\prime}-\mathrm{RACE}$ \\
\hline 3'-RACE inner & CCTGAAGGGGCACAAGAA & For $3^{\prime}$-RACE \\
\hline DMRT-3'F & CCTGAAGGGGCACAAGAA & For $3^{\prime}$-RACE \\
\hline DMRT-qF & ACGACCTTAGTAGGATGGACAGT & For RT-PCR \\
\hline DMRT-qR & GAGTGGAGGCAATAGAATGGGTA & For RT-PCR \\
\hline$\beta$-actinF & TATGCACTTCCTCATGCCATC & For RT-PCR \\
\hline$\beta$-actinR & AGGAGGCGGCAGTGGTCAT & For RT-PCR \\
\hline DMRT-P & САСТCCAGAATACTCGCCGAAGTCCTACGCGAAGAC & Probe foe ISH \\
\hline DMRT-iF & TAATACGACTCACTATAGGGCTTAGTGTCAGACGCGACCA & For DMRT dsRNA \\
\hline DMRT-iR & TAATACGACTCACTATAGGGCTTCGGCGAGTATTCTGGAG & For DMRT dsRNA \\
\hline IAG-qF & CGCCTCCGTCTGCCTGAGATAC & For RT-PCR \\
\hline IAG-qR & ССТССТССТССАССТТСААТGС & For RT-PCR \\
\hline VG-qF & GAAGTTAGCGGAGATCTGAGGT & For RT-PCR \\
\hline VG-qR & CCTCGTTGACCAATCTTGAGAG & For RT-PCR \\
\hline
\end{tabular}

\subsection{Tissue Expression Analysis by Quantitative Real-Time PCR}

After one week of culture in the laboratory, the eyestalk, brain, heart, hepatopancreas, gill, muscle, ovary, and testis were dissected from mature prawns $(n=5)$. The development of embryos was divided into seven stages based on a study of Bai et al. [26] (from the unfertilized egg (UE) to the first day larvae after hatching (L1)). The samples were dissected separately, immediately frozen in liquid nitrogen, and stored at $-80^{\circ} \mathrm{C}$ until processed.

The procedures for RNA isolation and cDNA synthesis were as described previously [21]. The expression profiles of MniDMRT11E in different tissues were determined using qPCR assays (CWBIO, Beijing, China) [21,41]. The relative copy numbers of MniDMRT11E mRNA were calculated according to the $2^{-\Delta \Delta C T}$ comparative $C T$ method [42]. Beta actin was constantly smooth expressed in different developmental stages of prawns. Bestkeeper analysis and similar methods were performed for expression levels of beta actin [43]. Differences in expression levels were considered significant at $p<0.05$.

\subsection{Expression Profiles of DMRT11E in Ovarian Cycle}

The determination of ovarian stage was based on the color of the oocytes, according to the criteria stated in [28]: Stage I (transparent), Stage II (yellow), Stage III (light green), Stage IV (dark green), and Stage V (gray). Ovarian samples were treated in the same way as other tissue. Then, we used qPCR to detect the expression level.

\subsection{In Situ Hybridization (ISH)}

ISH was performed on $4 \mu$-thick formalin fixed paraffin-embedded ovary and testis sections using the Zytofast PLUS CISH implementation kit, after they were embedded in paraffin, as described in [21]. The slides were examined under a light microscope. The anti-sense and sense probes of the chromogenic in-situ hybridization study were designed by Primer 5 software based on the cDNA sequence of MniDMRT11E. Both anti-sense and sense probes were hybridized with the slide. The anti-sense probe (5'-GTCUUCGCGUAGGACUUCGGCGAGUAUUCUGGAGUG-3') was prepared for the experimental group, whereas the sense probe $\left(5^{\prime}\right.$-CACUCCAGAAUACUCGCC GAAGUCCUACGCGAAGAC-3') was prepared for the control group. 


\subsection{RNA Interference of DMRT11E}

Deliberate dsDMRT11E synthesis and preservation were performed according to Li et al. [21]. The template for DMRT11E dsRNA synthesis was prepared by the amplification of testis cDNA with the primers DMRT-iF and DMRT-iR (Table 1). Eighty healthy mature female (stage I) prawns and 80 healthy mature male prawns were respectively assigned to two groups. The experimental group $(n=40)$ was injected with DMRT11E dsRNA (4 $\mathrm{g} / \mathrm{g}$ of body weight). DEPC water was injected at an equal dose based on gram body weight in the control group $(n=40)$. All tissues (androgenic gland, hepatopancreas, and gonad) from each group were randomly collected on the seventh day after the injection and dissected, frozen immediately in liquid nitrogen, and stored at $-80^{\circ} \mathrm{C}$ until analysis. $V G$ and DMRT11E mRNA expression in female tissue and IAG and DMRT11E mRNA expression in male tissue were investigated to detect the interference efficiency by qPCR on the seventh day after the injection $(n=4)$.

\subsection{Data Analysis}

All data are expressed as means \pm standard. Statistical differences were estimated by one-way ANOVA followed by LSD and Duncan's multiple range test in tissue distribution, embryo stages, and ovary cycle. A two-side t-test was used to compare expression levels in RNAi. All statistical analyses were performed using SPSS 20.0 (SPSS, Chicago, IL, USA).

Author Contributions: Conceived and designed experiments: Y.W., S.J. (Shubo Jin), H.F., H.Q., and S.S. Performed experiments: Y.W. and W.Z. Analyzed data: Y.W. Contributed reagents/materials/analysis tools: S.J. (Shubo Jin), Y.G., S.J. (Sufei Jiang), Y.X., and Y.W.

Funding: This research was supported by grants from the National Key R\&D Progrom of China (2018YFD0901303); the National Natural Science Foundation of China (31572617); the China Agriculture Research System-48 (CARS-48); the Science \& Technology Supporting Program of Jiangsu Province (BE2016308); Jiangsu Agricultural Industry Technology System JFRS-02; and the new cultivar breeding Major Project of Jiangsu province (PZCZ201745).

Conflicts of Interest: The authors declare no conflict of interest. The funders had no role in the design of the study; in the collection, analyses, or interpretation of data; in the writing of the manuscript, or in the decision to publish the results.

$\begin{array}{ll}\text { Abbreviations } \\ \text { DMRT } & \text { doublesex and mab-3 related transcription factor } \\ V G & \text { vitellogenin } \\ \text { IAG } & \text { insulin-like androgenic gland factor } \\ d s x & \text { doublesex } \\ \text { qPCR } & \text { quantitative real-time reverse transcription PCR } \\ \text { EM } & \text { eosinophilic matrix } \\ \text { E } & \text { eyestalk } \\ \text { BR } & \text { brain } \\ \text { H } & \text { heart } \\ \text { HE } & \text { hepatopancreas } \\ \text { G } & \text { gill } \\ \text { M } & \text { muscle; } \\ \text { O } & \text { ovary } \\ \text { T } & \text { testis } \\ \text { AG } & \text { abdominal ganglia } \\ \text { UE } & \text { unfertilized egg } \\ \text { CS } & \text { cleavage stage } \\ \text { BS } & \text { blastula stage } \\ \text { GS } & \text { gastrula stage } \\ \text { NS } & \text { nauplius stage } \\ & \end{array}$




$\begin{array}{ll}\text { ZS } & \text { zoea stage } \\ \text { L1 } & \text { the first day larvae after hatching } \\ \text { O I } & \text { undeveloped stage } \\ \text { O II } & \text { developing stage } \\ \text { O III } & \text { nearly-ripe stage } \\ \text { O IV } & \text { ripe stage } \\ \text { O V } & \text { spent stage } \\ \text { OG } & \text { oogonium } \\ \text { OC } & \text { oocyte } \\ \text { N } & \text { nucleus } \\ \text { CM } & \text { cytoplasmic membrane } \\ \text { Y } & \text { yolk granule } \\ \text { FC } & \text { follicle cell } \\ \text { FM } & \text { follicle membrane } \\ \text { CT } & \text { collecting tissue } \\ \text { SG } & \text { spermatogonium } \\ \text { SC } & \text { spermatocyte } \\ \text { SC1 } & \text { primary spermatocyte } \\ \text { SC2 } & \text { second spermatocyte } \\ \text { ST } & \text { spermatid } \\ \text { S } & \text { sperm } \\ \text { WE } & \text { wall epithelium } \\ \text { EM } & \text { eosinophilic matrix } \\ \text { VD } & \text { vas deferens } \\ \text { EB } & \text { open reading frame } \\ \text { ORF } & \text { Macrobrachium nipponense } \\ \text { M. nipponense } & \text { Macrobrachium rosenbergii } \\ \text { M. rosenbergii } & \text { complementary DNA } \\ \text { cDNA } & \text { freshwater Fisheries Research Centre } \\ \text { FFRC } & \text { in situ hybridization } \\ \text { CISH } & \end{array}$

\section{References}

1. Bureau of Fishery, Ministry of Agriculture, People's Republic of China. Fisheries Economic Statistics. In China Fishery Yearbook; China Agricultural Press: Beijing, China, 2018; p. 34.

2. Burtis, K.C.; Baker, B.S. Drosophila doublesex gene controls somatic sexual differentiation by producing alternatively spliced mRNAs encoding related sex-specific polypeptides. Cell 1989, 56, 997-1010. [CrossRef]

3. Martín, I.; Ruiz, M.F.; Sánchez, L. The gene transformer-2 of Sciara (Diptera, Nematocera) and its effect on Drosophila sexual development. BMC Dev. Biol. 2011, 11, 19. [CrossRef]

4. Ventura, T.; Manor, R.; Aflalo, E.D.; Weil, S.; Raviv, S.; Glazer, L.; Sagi, A. Temporal silencing of an androgenic gland-specific insulin-like gene affecting phenotypical gender differences and spermatogenesis. Endocrinology 2009, 150, 1278-1286. [CrossRef]

5. Chung, J.S.; Manor, R.; Sagi, A. Cloning of an insulin-like androgenic gland factor (IAG) from the blue crab, Callinectes sapidus: Implications for eyestalk regulation of IAG expression. Gen. Comp. Endocrinol. 2011, 173, 4-10. [CrossRef] [PubMed]

6. Ma, K.Y.; Lin, J.Y.; Guo, S.Z.; Chen, Y.; Li, J.L.; Qiu, G.F. Molecular characterization and expression analysis of an insulin-like gene from the androgenic gland of the oriental river prawn, Macrobrachium nipponense. Gen. Comp. Endocrinol. 2013, 185, 90-96. [CrossRef]

7. Vega-Alpízar, J.L.; Alfaro-Montoya, J.; Hernández-Noguera, L.; Umaña-Castro, R.; Aflalo, E.D.; Sagic, A. Implant recognition and gender expression following ampoule-androgenic gland implantation in Litopenaeus vannamei females (Penaeidae). Aquaculture 2017, 468, 471-480. [CrossRef] 
8. Guo, Q.; Li, S.; Lv, X.; Xiang, J.; Sagi, A.; Manor, R.; Li, F. A Putative Insulin-like Androgenic Gland Hormone Receptor Gene Specifically Expressed in Male Chinese Shrimp. Endocrinology 2018, 159, $2173-2185$. [CrossRef]

9. Zhang, E.F.; Qiu, G.F. A novel Dmrt gene is specifically expressed in the testis of Chinese mitten crab, Eriocheir sinensis. Dev. Genes Evol. 2010, 220, 151-159. [CrossRef] [PubMed]

10. Yu, Y.Q.; Ma, W.M.; Zeng, Q.G.; Qian, Y.Q.; Yang, J.S.; Yang, W.J. Molecular Cloning and Sexually Dimorphic Expression of Two Dmrt, Genes in the Giant Freshwater Prawn, Macrobrachium rosenbergii. Agric. Res. 2014, 3, 3181-3191. [CrossRef]

11. Raymond, C.S.; Murphy, M.W.; O'Sullivan, M.G.; Bardwell, V.J.; Zarkower, D. Dmrt1, a gene related to worm and fly sexual regulators, is required for mammalian testis differentiation. Genes Dev. 2000, 14, 2587-2595. [CrossRef]

12. Raymond, C.S.; Shamu, C.E.; Shen, M.M.; Seifert, K.J.; Hirsch, B.; Hodgkin, J.; Zarkower, D. Evidence for evolutionary conservation of sex-determining genes. Nature 1998, 391, 691-695. [CrossRef]

13. Artyom, K. Dmrt, genes in the development and evolution of sexual dimorphism. Trends Genet. 2012, 28, 175-184.

14. Erdman, S.E.; Burtis, K.C. The Drosophila doublesex proteins share a novel zinc finger related DNA binding domain. The EMBO journal 1993, 12, 527-535. [CrossRef]

15. Murphy, M.W.; Lee, J.K.; Rojo, S.; Gearhart, M.D.; Kurahashi, K.; Banerjee, S.; Loeuille, G.A.; Bashamboo, A.; McElreavey, K.; Zarkower, D.; et al. An ancient protein-DNA interaction underlying metazoan sex determination. Nat. Struct. Mol. Biol. 2015, 22, 442-451. [CrossRef]

16. Zhang, T.; Zarkower, D. DMRT proteins and coordination of mammalian spermatogenesis. Stem Cell Res. 2017, 24, 195-202. [CrossRef]

17. Hildreth, P.E. doublesex, recessive gene that transforms both males and females of drosophila into intersexes. Genetics 1965, 51, 659-678.

18. Shen, M.M.; Hodgkin, J. mab-3, a gene required for sex-specific yolk protein expression and a male-specific lineage in C. elegans. Cell 1988, 54, 1019-1031. [CrossRef]

19. Picard, M.A.; Cosseau, C.; Mouahid, G.; Duval, D.; Grunau, C.; Toulza, E.; Allienne, J.F.; Boissier, J. The roles of Dmrt (Double sex/Male-abnormal-3 Related Transcription factor) genes in sex determination and differentiation mechanisms: Ubiquity and diversity across the animal kingdom. Comptes Rendus Biol. 2015, 338, 451-462. [CrossRef] [PubMed]

20. Kato, Y.; Kobayashi, K.; Oda, S.; Colbourn, J.K.; Tatarazako, N.; Watanabe, H.; Iguchi, T. Molecular cloning and sexually dimorphic expression of DM-domain genes in Daphnia magna. Genomics 2008, 91, 94-101. [CrossRef]

21. Li, F.; Qiao, H.; Fu, H.; Sun, S.; Zhang, W.; Jin, S.; Jiang, S.; Gong, Y.; Xiong, Y.; Wu, Y.; et al. Identification and characterization of opsin gene and its role in ovarian maturation in the oriental river prawn Macrobrachium nipponense. Comp. Biochem. Physiol. Part B Biochem. Mol. Biol. 2018, 218, 1-12. [CrossRef]

22. Kim, B.M.; Jeong, C.B.; Kim, I.C.; Yim, J.H.; Lee, Y.S.; Rhee, J.; Lee, J. Identification of three doublesex genes in the monogonont rotifer Brachionus koreanus and their transcriptional responses to environmental stressor-triggered population growth retardation. Comp. Biochem. Physiol. Part B Biochem. Mol. Biol. 2014, 174, 36-44. [CrossRef]

23. Qiu, G.; Du, N.; Lai, W. Studies on the male reproductive system of the freshwater praan, Macrobrachium nipponense: II. The morphology and ultrastructure of the sperm. Acta Zool. Sin. 1996, 42, 349-354.

24. Qiao, H.; Xiong, Y.; Zhang, W.; Fu, H.; Jiang, S.; Sun, S.; Bai, H.; Jin, S.; Gong, Y. Characterization, expression, and function analysis of gonad-inhibiting hormone in Oriental River prawn, Macrobrachium nipponense and its induced expression by temperature. Comp. Biochem. Physiol. Part A Mol. Integr. Physiol. 2015, 185, 1-8. [CrossRef]

25. Phoungpetchara, I.; Tinikul, Y.; Poljaroen, J.; Chotwiwatthanakun, C.; Vanichviriyakit, R.; Sroyraya, M.; Hanna, P.J.; Sobhon, P. Cells producing insulin-like androgenic gland hormone of the giant freshwater prawn, Macrobrachium rosenbergii, proliferate following bilateral eyestalk-ablation. Tissue Cell 2011, 43, 165-177. [CrossRef] [PubMed]

26. Bai, H.; Qiao, H.; Li, F.; Fu, H.; Jiang, S.; Zhang, W.; Yan, Y.; Xiong, Y.; Sun, S.; Jin, S.; et al. Molecular and functional characterization of the vitellogenin receptor in oriental river prawn, Macrobrachium nipponense. Comp. Biochem. Physiol. Part A Mol. Integr. Physiol. 2016, 194, 45-55. [CrossRef] [PubMed] 
27. Bellefroid, E.J.; Leclere, L.; Saulnier, A.; Keruzore, M.; Sirakov, M.; Vervoort, M.; De Clercq, S. Expanding roles for the evolutionarily conserved Dmrt sex transcriptional regulators during embryogenesis. Cell. Mol. Llife Sci. 2013, 70, 3829-3845. [CrossRef] [PubMed]

28. Wexler, J.R.; Plachetzki, D.C.; Kopp, A. Pan-metazoan phylogeny of the DMRT gene family: A framework for functional studies. Dev. Genes Evol. 2014, 224, 175-181. [CrossRef] [PubMed]

29. Zhu, L.; Wilken, J.; Phillips, N.B.; Narendra, U.; Chan, G.; Stratton, S.M.; Kent, S.B.; Weiss, M.A. Sexual dimorphism in diverse metazoans is regulated by a novel class of intertwined zinc fingers. Genes Dev. 2000, 14, 1750-1764.

30. Lourenço, R.; Lopes, S.S.; Saúde, L. Left-Right Function of dmrt2 Genes Is Not Conserved between Zebrafish and Mouse. PLoS ONE 2010, 5, e14438. [CrossRef] [PubMed]

31. Seo, K.W.; Wang, Y.; Kokubo, H.; Kettlewell, J.R.; Zarkower, D.A.; Johnson, R.L. Targeted disruption of the DM domain containing transcription factor Dmrt2 reveals an essential role in somite patterning. Dev. Biol. 2006, 290, 200-210. [CrossRef]

32. Wilder, M.N.; Okumura, T.; Tsutsui, N. Reproductive mechanisms in Crustacea focusing on selected prawn species: Vitellogenin structure, processing and synthetic control. Aqua Biosci. Monogr. 2010, 3, 73-110. [CrossRef]

33. Yi, W.; Zarkower, D. Similarity of DNA binding and transcriptional regulation by Caenorhabditis elegans MAB-3 and Drosophila melanogaster DSX suggests conservation of sex determining mechanisms. Development 1999, 126, 873-881.

34. Zhang, X.; Zha, J.; Wang, Z. Influences of 4-nonylphenol on doublesex-and mab-3-related transcription factor 1 gene expression and vitellogenin mRNA induction of adult rare minnow (Gobiocypris rarus). Environ. Toxicol. Chem. 2008, 27, 196-205. [CrossRef]

35. Shukla, J.N.; Palli, S.R. Doublesex target genes in the red flour beetle, Tribolium castaneum. Sci. Rep. 2012, 2, 948. [CrossRef]

36. Ventura, T.; Manor, R.; Aflalo, E.D.; Weil, S.; Rosen, O.; Sagi, A. Timing sexual differentiation: Full functional sex reversal achieved through silencing of a single insulin-like gene in the prawn, Macrobrachium rosenbergii. Biol. Rreprod. 2012, 86, 1-6. [CrossRef]

37. Shechter, A.; Glazer, L.; Cheled, S.; Mor, E.; Weil, S.; Berman, A.; Bentov, S.; Aflalo, E.D.; Khalaila, I.; Sagi, A. A gastrolith protein serving a dual role in the formation of an amorphous mineral containing extracellular matrix. Proc. Natl. Acad. Sci. USA 2008, 105, 7129-7134. [CrossRef]

38. Bai, H.; Qiao, H.; Li, F.; Fu, H.; Sun, S.; Zhang, W.; Jin, S.; Gong, Y.; Jiang, S.; Xiong, Y. Molecular characterization and developmental expression of vitellogenin in the oriental river prawn Macrobrachium nipponense and the effects of RNA interference and eyestalk ablation on ovarian maturation. Gene 2015, 562, 22-31. [CrossRef]

39. French, A.S.; Meisner, S.; Liu, H.; Weckström, M.; Torkkeli, P.H. Transcriptome analysisand RNA interference of cockroach phototransduction indicate three opsins and suggest a major role for TRPL channels. Front. Physiol. 2015, 6, 207. [CrossRef]

40. Subramoniam, T. Mechanisms and control of vitellogenesis in crustaceans. Fisheries. Sci. 2011, 77, 1-21. [CrossRef]

41. Zhang, Y.; Jiang, S.; Xiong, Y.; Sun, S.; Qiao, H.; Jin, S.; Gong, Y.; Fu, H. Molecular cloning and expression analysis of extra sex combs gene during development in Macrobrachium nipponense. Turk. J. Fish. Aquat. Sci. 2013, 13, 331-340. [CrossRef]

42. Livak, K.J.; Schmittgen, T.D. Analysis of relative gene expression data using real-time quantitative PCR and the $2^{-\Delta \Delta C T}$ method. Methods 2001, 25, 402-408. [CrossRef]

43. Hu, Y.; Fu, H.; Qiao, H.; Sun, S.; Zhang, W.; Jin, S.; Jiang, S.; Gong, Y.; Xiong, Y.; Wu, Y. Validation and evaluation of reference genes for quantitative real-time PCR in Macrobrachium Nipponense. Int. J. Mol. Sci. 2018, 19, 2258. [CrossRef] [PubMed]

(C) 2019 by the authors. Licensee MDPI, Basel, Switzerland. This article is an open access article distributed under the terms and conditions of the Creative Commons Attribution (CC BY) license (http://creativecommons.org/licenses/by/4.0/). 